\title{
A VIVÊNCIA DO DESEMPREGO POR JOVENS APRENDIZES
}

\section{Unemployment Experience in Young Apprentices}

\author{
Maria Sara de Lima Dias ${ }^{1}$ \\ YáraL.M.Bulgacov ${ }^{2}$ \\ Denise de Camargo ${ }^{3}$
}

\section{Resumo}

Este artigo revela a vivência subjetiva de jovens que, após passarem por um programa de qualificação profissional como aprendizes, encontram-se na situação de desemprego. Considerando a subjetividade como socialmente enraizada, busca-se, junto às narrativas destes jovens, as marcas de nosso momento social, político e econômico. A pesquisa, ao se configurar como estudo de casos múltiplos de natureza qualitativa, toma como dados empíricos as narrativas de jovens aprendizes em situação de desemprego qualificado. A análise destas narrativas demonstra dois movimentos: o da inserção e o da exclusão. A identidade neste processo é ambígua, relacionada ao tempo em que permaneceram na empresa e à condição de excluídos. Igualam-se e distinguem-se dos demais desempregados. Pela experiência profissional e pelo diploma adquirido, sentem-se qualificados para o trabalho. Ao vivenciarem o papel de excluídos do trabalho, sentem o desemprego como culpa sua. Suas emoções, cognição e ação estão constantemente implicadas na busca de emprego, para repor uma identificação com um papel anteriormente posto, repercutindo na subjetividade desses jovens. Os indicadores mostram que os programas de formação profissional precisam ser estudados criticamente: não conseguem cumprir a meta para a qual foram criados, correm, assim, o risco de ser reduzidos à propaganda dos gestores desses programas.

Palavras-chave: Desemprego; Vivência subjetiva; Identidade profissional.

\footnotetext{
Mestre em Psicologia pela Universidade Federal do Paraná (UFPR) e Professora Substituta do Departamento de Psicologia da Universidade Federal de Santa Catarina (UFSC).e-mail: diassara@hotmail.com ou diassara@terra.com.br

2 Professora Doutora do Mestrado em Administração do Centro Universitário Positivo (UnicenP). Curitiba-PR. e-mail: unicenp.ybulgacov@terra.com.br e-mail: denisedecamargo@uol.com.br

3 Professora Doutora aposentada da Universidade Federal do Paraná. Curitiba-PR
} 


\section{Abstract}

This article discloses the experience subjective of young that after to pass for a program of professional qualification as apprentices meets in the situation of total unemployed. Considering the subjectivity as socially taken root one searchs the narratives of these young together the marks of our social moment, economic and politician. The research to if configuring as study of multiple cases of qualitative nature, take as given empirical the narratives of young apprentices in situation of qualified unemployment. The analysis of these narratives demonstrates two movements: that of insertion and that of exclusion. The identity in this process is ambiguous, related to the time they had a job in an enterprise and to their condition of excluded persons. They are equaled and they distinguished from excessively the unemployeds. For the professional experience and the acquired diploma, they are felt qualified for the work. When they experience the role of exclusion from work, they feel that unemployment is their fault. Their emotions, cognition and actions are constantly implied in their search of a job. Through that search they aim at identifying themselves to a role previously put, bearing influence as processes that subjectivity of young persons. The pointers show that the programs of professional formation need to be studied in criticizes : they do not obtain to fulfill the goal for which they had been servant, they run thus, the risk of being reduced to the propaganda of the managers of these programs.

Keywords: Unemployment; Experience; Subjectivity; Professional identity.

\section{Introdução}

As atuais mudanças no mundo do trabalho deixam visíveis alterações nas suas formas de organização e nos paradigmas produtivos, agravando o desemprego. No Brasil, pode-se observar dois períodos em relação ao mercado de trabalho e ao desemprego. O primeiro, entre 1940 e 1980, é marcado pelo movimento de estruturação do mercado de trabalho decorrente do processo de industrialização e institucionalização das relações e condições de trabalho, e o segundo período, de 1980 até nossos dias, caracteriza-se pela desestruturação do mercado de trabalho e adoção das políticas neoliberais - momento da desaceleração no número de ocupações e expansão do desemprego, afetando diversos segmentos da população (Pochman, 2000).

Do ponto de vista do impacto do desemprego na camada jovem da população, é interessante acompanhar o que constata a Organização Internacional do Trabalho (OIT) ao declarar que existem atualmente mais de 70 milhões de jovens desempregados no mundo. Estima-se, ainda, que a taxa de desemprego entre jovens é pelo menos duas vezes maior que a da média dos adultos. Conforme pesquisa do Instituto de Pesquisa Econômica Aplicada (Ipea, 2003), destacam-se as faixas de 15 a 19 anos e de 20 a 24 anos, que concentram 4,9 milhões de desempregados, no Brasil.

Em face dessa realidade, instituições voltadas à qualificação profissional tomam medidas que visam contribuir para minimizar o problema, envolvendo tanto organizações governamentais como não-governamentais e criando mecanismos para oportunizar o ingresso do jovem no mercado de trabalho. O Programa do Primeiro Emprego e o Programa do Menor Aprendiz, do governo federal, são exemplos dessas políticas. $O$ presente estudo está centrado no Programa do Menor Aprendiz.

O Programa do Menor Aprendiz (PMA) conceitua como menor o jovem de quatorze a dezoito anos. Criado pela Lei n. ${ }^{\circ}$ 10.097/2000, da CLT, estabelece a obrigatoriedade da empresa de empregar e matricular em cursos de qualificação de 5\% a $15 \%$ do seu quadro de trabalhadores cujas funções demandem formação profissional. O modelo adotado pelo PMA vincula a formação técnica específica, fornecida geralmente por órgãos como o Senai (Serviço Nacional de Aprendizagem Profissional) e escolas técnicas regulamentadas, à obrigatoriedade da freqüência do aluno aprendiz a uma formação regular geralmente ministrada nas escolas noturnas, e, por extensão, de forma complementar a esta formação, exige a vivência prática em uma empresa, onde o aluno desempenha o papel de aprendiz. A prática disciplinar de uma rotina envolvendo escola técnica, ensino regular e empresa visa fornecer ao aprendiz a qualificação profissional necessária para que ele se mantenha no mercado de trabalho.

A qualificação profissional tem sido estudada desde a década de 1940, quando predominava a organização taylorista/fordista do 
trabalho, adquirindo, entretanto, novo destaque a partir da década de 1980, em virtude das transformações tecnológicas, econômicas, políticas e culturais que atingiram o mundo do trabalho. Passou de um "modelo de produção rígida" para um "novo paradigma de produção", assentado na "especialização flexível", demandando do trabalhador não apenas conhecimentos objetivos, formais e explícitos, mas também amplas habilidades cognitivas e comportamentais, como iniciativa, criatividade, cooperação, liderança, etc., para enfrentar os imprevistos da produção.

Nesse contexto, nossa prática profissional, desenvolvida desde 2000 no Programa do Menor Aprendiz (PMA), suscitou algumas reflexões que acabaram por definir o tema da pesquisa que passaremos a relatar com mais detalhes. A pesquisa teve como objetivo principal conhecer e compreender como os jovens que participaram do PMA vivenciaram a situação de desemprego experimentada a partir do momento em que completaram a maioridade.

$\mathrm{Na}$ busca de inserção do jovem no mercado de trabalho, o PMA determina regras e condições específicas para esta formação: a primeira regra é a seleção para a entrada no programa, sendo que de cada cem jovens inscritos, somente dez são aprovados nos exames seletivos. Estes exames compreendem provas de português, matemática e avaliação psicológica. A segunda condição, voltada à formação técnica, é a comprovação de sua qualificação por meio da elaboração de um projeto específico conforme a área técnica de trabalho. A terceira condição é dada pela formação regular, determinando a freqüência às aulas, boas notas e o não abandono do ensino regular como requisitos fundamentais para que o aluno permaneça no PMA. A partir da vivência profissional, realizada geralmente no contexto de uma grande indústria, o jovem deve cumprir as normas da empresa, os horários e demais rotinas de trabalho inerentes ao contexto organizacional. Portanto, a aprendizagem é efetuada numa exaustiva jornada diária de três turnos entre a escola de ensino regular, a freqüência ao Senai e ao estágio na empresa, rotina esta compreendida em um período de seis meses até dois anos.

Uma questão que, de início, nos chamou a atenção foi a de que o contrato estabelecido entre a empresa, a instituição de aprendizagem e o jovem revelava alguns mecanismos intrínsecos e contraditórios. Tendo como objetivo a qualificação profissional do jovem, o programa, tal como está desenhado, encerra uma grande contradição. Constatamos que parcelas significativas desses jovens, ao completarem dezoito anos, não são absorvidas pela empresa em que fazem a qualificação, porque a empresa busca novos aprendizes a cada ano, mantendo o ciclo de admissões e desligamentos. Ou seja, o programa não possui mecanismos para incentivar as empresas a contratarem os jovens, pois isso significaria, para elas, abrir um novo posto de trabalho e, ao mesmo tempo, perder os benefícios e incentivos legais do contrato de aprendizes. Tampouco o programa tem facilitado a inserção desses jovens no mercado de trabalho devido à especificidade de sua formação técnica, extremamente direcionada aos objetivos da empresa onde realizam a aprendizagem, as rápidas alterações de tecnologias no ambiente das empresas e à pouca experiência profissional adquirida durante este período.

Assim, o PMA, ao qualificar, exclui o jovem, qualificando-o ao desemprego. Como o jovem vivencia esta contradição? Quais são as explicações que ele constrói para compreender a experiência contraditória que vivencia? Quais as marcas dessas contradições na identidade destes? Estas são algumas das perguntas que surgiram da convivência próxima com esses jovens, às quais procuramos responder nesta pesquisa.

Encontramos a justificativa para este estudo no caráter contraditório das transformações do mundo do trabalho, que, ao mesmo tempo, exige um grande esforço pessoal de qualificação e exclui o sujeito do meio de sobrevivência, na medida em que, cada vez mais, configura-se uma sociedade com poucas oportunidades de trabalho. Em relação aos jovens, os indicadores mostram que os programas de formação profissional precisam ser estudados criticamente, isso porque se não conseguem cumprir a meta para a qual foram criados, correm o risco de ser reduzidos à propaganda dos gestores desses programas.

\section{Abordagem teórico-metodológica da pesquisa}

O Senai de Curitiba, eleito como fonte privilegiada para a pesquisa em questão, é o órgão oficial do Estado ligado ao programa federal de formação e qualificação de menores aprendizes.

O foco da pesquisa foi a narrativa de jovens aprendizes de 16 a 24 anos que se encontravam na situação de desemprego total e que haviam passado pelo Programa do Menor Aprendiz do Senai. Conceitua-se como desemprego total a condição em 
que se constatam: a) o desemprego aberto (em que a pessoa não trabalhou mas procura trabalho na semana); b) o desemprego oculto pelo trabalho precário (procura de trabalho concomitante a alguma atividade irregular nos últimos trinta dias); c) desemprego oculto pelo desalento (sem trabalho na semana e sem procura de trabalho nos últimos trinta dias, mas com procura nos últimos doze meses).

Os dados analisados foram coletados em entrevistas narrativas que, conforme a técnica de Bauer e Grastell (2002), tem em vista criar uma situação que encoraje e estimule o jovem a contar a história sobre sua vivência enquanto recente aprendiz a trabalhador desempregado. A opção por esta forma de coleta de dados, que pode ser caracterizada como uma entrevista não-estruturada, de profundidade, deu-se pela perspectiva de compreender as vivências subjetivas desses jovens a partir de como narram e interpretam suas experiências.

Os procedimentos da pesquisa contemplaram: a) entrada no campo: solicitação de listagens de ex-alunos; b) contato com jovens que se dispusessem a participar deste projeto de pesquisa; c) agenda de entrevistas com os sujeitos selecionados, com apresentação do termo de consentimento livre e esclarecido; d) preparação das entrevistas; e) gravação das entrevistas; d) transcrição e análise das entrevistas. $O$ roteiro da entrevista foi dividido nos seguintes eixos: a história profissional, a vivência de inserção/exclusão do trabalho e os projetos de vida.

Relativamente à história profissional, buscou-se recuperar as escolhas e direções dadas ao projeto profissional: a trajetória objetiva de inserção no mundo do trabalho. A análise da vivência da inserção centrou-se em aspectos da formação, no início da condição de trabalhador, nos valores do trabalho e da aprendizagem. Quanto à construção dos projetos de vida, a investigação voltou-se para as marcas das condições objetivas de classe social. Ao abordar a vivência do desemprego, buscaram-se aspectos relacionados aos sentidos produzidos pela condição concreta em que se encontravam esses jovens. Ao se falar sobre os projetos de vida, procuraram-se expectativas de futuro e estratégias adotadas para atingirem seus objetivos de futuro pessoal e profissional.

O próprio encaminhar das entrevistas indicou o número adequado destas, satisfazendo ao critério de saturação, isto é, o ponto em que as entrevistas não mais fornecem dados novos.
O critério de saturação é atingido quando se permite uma reincidência das informações (Minayo, 2002). Constatamos que, após cinco entrevistas, os dados levantados começam a se repetir nas narrativas dos jovens.

A possibilidade de compartilhar a narrativa faz dela uma obra aberta, sem explicações definitivas, admitindo-se diversas interpretações. Seu não-acabamento se apóia na plenitude do sentido e em sua profusão ilimitada, de tal modo que cada história enseja outra história, suscita novas histórias. Captar esta dimensão particular, singular, do movimento do indivíduo com a dinâmica social (cultural) no processo de aculturação (que é geral), apreendendo o que o diferencia e o que o identifica com os demais membros de sua cultura, é o diferencial da abordagem qualitativa escolhida. Tornar esta lógica visível é nossa tarefa de pesquisadores e, uma vez apropriada pelo sujeito, é caminho para a tomada de consciência de si mesmo.

O pressuposto teórico orientador da pesquisa é o entendimento de que o ser humano é um constante vir-a-ser que se move em busca do ser, de compreender quem ele é, de construir uma identidade que expresse sua singularidade. Quando conta sua história ou narra algum episódio de sua vida, o indivíduo está produzindo sentidos para significar cada passagem biográfica. Seu tempo de vida e experiências constroem processos carregados de sentido objetivo e subjetivo.

Considerando a identidade construída socialmente (Abib, 2001) indagava-se: quais as marcas que esta condição objetiva vivenciada por esses jovens imprimiram em sua subjetividade? Entende-se que o indivíduo encarna as relações sociais, configurando sua identidade pessoal, e também constrói uma história, um projeto de vida que pode ser entendido como uma narrativa.

Considerando a contradição mencionada acima, ou seja, tratar-se de um programa que, ao qualificar, exclui o jovem, qualificando-o ao desemprego, tinha-se como objetivo analisar as implicações do desemprego na subjetividade do jovem. Para tanto, recorremos à experiência vivida de inclusão no mundo do trabalho e de posterior exclusão.

Ao abordar a narrativa, entendemos esta como relato centrado num fato ou acontecimento; há as ações de personagens e um narrador que as relata. O tempo e o ambiente ou cenário são outros elementos imprescindíveis na estrutura da narração. As narrativas apreendidas revelam diferentes 
implicações do desemprego, mostrando as relações e contradições entre identidade, emoção, vivências e projetos de vida.

Considerando a opção teóricometodológica adotada, segue-se a conceituação sintética das principais categorias teóricas de análise eleitas para este estudo. Ressalte-se o esforço de integrar essas categorias para apreender a totalidade sócio-histórica do indivíduo.

A identidade, que surge como representação do meu estar-sendo no mundo, converte-se num pressuposto de meu ser, como totalidade, o que transforma minha identidade concreta - um dar-se numa sucessão temporal - em identidade abstrata (num dado atemporal sempre presente), entendida como identidade pressuposta re-posta. Buscamos articular a noção de identidade formulada por Ciampa (1987) com a narrativa dos jovens desempregados, visando ilustrar o movimento da identidade em sua dimensão concreta e abstrata considerada neste estudo.

A emoção, dimensão humana intrinsecamente presente observada nas relações cotidianas, possui a função de dar significação ao real, de conferir sentido ao ato. A emoção tem lugar equivalente ao da cognição, na constituição da psique; é resultado da apreciação que faz o próprio organismo em sua relação com o meio. Buscamos integrar os conceitos de emoção e subcategorias desenvolvidos por Rimé (1993), Vigotsky (1998), Maturana (1999) e Heller (1993) com o conceito de sofrimento psicossocial desenvolvido por Sawaia (1995) e Carreteiro (2002).

A vivência aparece no pensamento de Vigotsky (1998) como unidade da situação social de desenvolvimento do homem concreto; significa a posição do indivíduo em cada etapa de sua vida, compreendendo cada etapa como a relação interna do indivíduo e sua posição objetiva no sistema de relações sociais. Etapas vivenciadas adquirem fundamental importância na vida do jovem, orientando-o quanto à direção na elaboração de seus projetos de vida. O conceito de vivência representa a unidade indissolúvel de elementos internos e externos que se expressam integrados em aspectos cognitivos e afetivos.

O conceito de projetos de vida permite revelar muitas das implicações do desemprego na subjetividade deste jovem. D'Ângelo (2000) e Velho (1999) entendem projeto como categoria básica da análise da identidade. O projeto é o que vai direcionar o ser para o futuro; projeto no sentido de que o ser humano absorve determinados papéis sociais. Na dialética entre o indivíduo e a sociedade, a constituição da identidade implica intencionalidade da ação humana. O ser desenvolve projetos de si mesmo, um vir a ser, constantemente orientado para o futuro como possibilidade de ser.

A partir dessas categorias teóricas de identidade, emoção, vivência e projetos de vida, passa-se à análise das narrativas, buscando reintegrar os sentidos na subjetividade, correlacionando-as com a situação objetiva de desemprego.

\section{Resultado e análise dos dados}

As entrevistas, com duração média de 1 hora e 30 minutos, foram realizadas na casa dos entrevistados. Todos os aprendizes pesquisados residem em bairros periféricos de Curitiba, Paraná, passaram pelo Programa para Menores Aprendizes, do governo federal, trabalharam e encontram-se em situação de desemprego total. Suas famílias são formadas por operários de indústrias, auxiliares e vendedores em lojas. Dentre os jovens, três estão cursando o ensino médio e dois já o concluíram.

A narrativa do dia-a-dia do jovem aprendiz sobre sua vivência de inclusão e exclusão do mundo do trabalho fez emergir dimensões em que esses atores sociais se integravam a um contexto micro e macrossocial, as quais determinam o seu modo de pensar, sentir e agir na e para a vida. Entendemos que cada indivíduo incorpora as relações sociais, configurando uma identidade pessoal, uma história de vida, um projeto de vida, mediado por relações sociais, em instituições sociais onde o ensino profissional diferencia uma posição específica de trajetória de vida, permitindo tanto a vivência da inclusão como da exclusão do mundo do trabalho.

Porém, nenhum indivíduo interioriza a totalidade daquilo que é objetivado como realidade em sua sociedade. A complexa subjetividade humana decorre de um processo de desenvolvimento profundamente enraizado na ligação entre história individual e história social. A crise nacional promovida pela desaceleração da economia tem gerado o crescimento do desemprego em todas as regiões brasileiras. Especificamente em Curitiba, revela um contingente de 120.000 jovens desempregados. Todos os indicadores apontam uma conjuntura de crescente preocupação com as dificuldades de trabalho para jovens, bem como as 
possibilidades de estes conseguirem oportunidades concretas de se inserir no mercado de trabalho.

Considerando esses aspectos objetivos e pressupondo que o desemprego marca a vivência do jovem, este projeto objetivou compreender como os jovens aprendizes vivenciam subjetivamente o desemprego, considerando, como já colocado, que estas posições objetivas se articulam e repercutem na subjetividade dos jovens e na formação de suas identidades.

Neste percurso, focalizamos dois movimentos distintos: o da inserção e o da exclusão, que repercutem na subjetividade do jovem. $\mathrm{Na}$ inserção, o jovem estabelece como objetivo ser empregado em uma grande empresa, tal como expresso nesta fala: "Aqui no Senai todo mundo consegue". Para alcançar o que se propôs, enfrenta a seletividade e a dura jornada de deslocamentos entre o lar, a escola, a empresa e a instituição de formação. Ante o cansaço e a falta de tempo para estudar, e mesmo dormir, se esforça, sempre na expectativa do emprego em uma grande empresa: "Eu era de domingo a domingo. Bem, eu trabalhava no período da manhã, das seis às três da tarde. Chegava em casa às quatro e saía às seis. Não tinha tempo para nada, nem para dormir não dava". No papel de trabalhador, interioriza valores positivos e afirmativos do trabalho. Subjetivamente, ser trabalhador é cumprir seus deveres e obrigações; mais que isso: é buscar liberdade de ação e autonomia. “... e a sensação que dá quando você tem o seu dinheiro é de liberdade". Forja uma identidade para o outro, confunde-se com o papel de trabalhador que representa, com a função que exerce em cada etapa de sua vida profissional "Eu era eletrônico, Eu era gravador off-set. Eu era impressor., Lá eu era estagiário".

A rotina desses jovens é integralmente envolvida pela condição de ser aprendiz. Poderíamos perguntar: o que mobiliza esses jovens? $\mathrm{O}$ que faz com que suas outras necessidades e interesses, tão comuns nos jovens em nossa cultura, sejam deixados de lado e toda a energia fique voltada para a condição de aprendiz? O que mantém esta implicação na atividade de aprender no trabalho, de dia, e ainda, à noite, ir para a escola? A fala dos jovens entrevistados é indicadora do que mobiliza e mantém a implicação com o programa de aprendiz: "O trabalho, para o jovem, ajuda a dar direção na vida". Em outro momento, afirma: "Agora eu tenho certeza que vou fazer Engenharia Eletrônica. No Cefet ou Federal, onde eu conseguir passar". Fica claro, nesta fala, que o Programa gera nesses jovens expectativas e sonhos, e que este é o fator determinante que mantém a motivação e o empenho no trabalho e na escola. Revelam projetos de carreira em grandes empresas e de continuar os estudos.

O outro movimento, já mencionado, é o da exclusão, quando o jovem mostra sentimentos de inadequação frente ao papel que atualmente representa: "Por enquanto eu não tenho profissão. Não tenho como pensar e nem como ganhar dinheiro". "Tenho alguma experiência, mas não é muita... não é suficiente". Desenvolve estratégias de enfrentamento: atividades caseiras, pequenos trabalhos temporários, os "bicos", tentativas de voltar para a empresa de origem e busca de outras colocações no mercado. "Agora eu fico em casa dia todo... às vezes eu saio um pouco para distrair, para espairecer um pouco". "Eu cuido do cachorro... fico em casa o dia todo esperando o telefone tocar". Vivenciando o desemprego como sua culpa, volta sua rotina à busca de emprego, visando repor a identificação com um papel anteriormente posto. "Entraram vinte, mas não ficou nenhum. Quando nós entramos lá, já tinha acho que uns doze ou treze que estavam terminando o Senai. Daí entrou no outro ano... entrou mais uma turma, uns vinte, todo mundo saiu. Eu entrei na época do facão. Eles falaram que era remanejamento. Na hora deu um choque, que eu não sabia nem o que falar". Enfrenta a rotina de enviar currículos e esperar que algo aconteça. Como se forjou uma identidade para o outro, quer apenas ter um emprego.

Muitas vezes carrega a identidade de jovem desempregado como um fardo: "Eu tenho qualificação profissional, não muita, mas agora tá diferente, tipo no mesmo ramo. Na gráfica, na área que eu trabalhei, eu conheço bastante, mas já não tem... Já fui, né?” Ele tem qualificação, mas esta ainda é pouca; possui experiência, mas não suficiente para cumprir as novas demandas do mercado. "É difícil pegar, porque tem que ter mais experiência do que eu tenho... Se você olhar no jornal é no mínimo de três ou quatro anos".

Subjetivamente, interiorizou a imagem negativa do trabalhador desempregado como parasita, vagabundo - pessoa que "fica só no bembom" -, inútil aos olhos da sociedade. São explicações e razões que fazem parte de nossa cultura. É importante lembrar que, com os saberes profissionais ou técnicos, os jovens assimilam saberes ideológicos. Aprendem comportamentos adequados e 
internalizam valores do que é ser um bom trabalhador. Os modelos de trabalhadores exemplares que conheceram e, por outro lado, os valores de depreciação em relação aos desempregados que assimilaram oferecem os elementos ideológicos para o jovem compreender sua situação no mundo. "Agora... tipo, eu sou um inútil, para falar a verdade... Sim, porque hoje em dia eu não faço nada". Compreendemos, pelas suas narrativas, que a situação de classe, a questão etária, o local de residência, as oportunidades de vagas em empresas, a gratuidade e as limitadas ofertas de cursos específicos são as condições que determinam objetivamente a inserção precoce do jovem no mercado de trabalho promovida pelo PMA. "A escolha, sei lá, foi meio que... meio que na louca mesmo. Lá perto de casa só tinha esses cursos de Elétrica e Eletrônica, mas eu não sabia nada de nenhum dos dois".

Nessas condições objetivas, sua identidade de trabalhador é posta num ordenamento; pela freqüência à escola técnica os jovens são incluídos num seleto mercado, onde somente os melhores alunos, os mais esforçados aprendizes, encontram possibilidades concretas de entrar. São pequenos grandes talentos. "Lá eu trabalhei direito, entendeu? $\mathrm{O}$ que me pediam eu fazia. Fazia até mais do que pediam, assim..."

A identidade como aquele ser no mundo com o qual me reconheço finca aqui uma de suas estacas, constituindo-se objetiva/subjetivamente nestas relações com a instituição família, escola, empresa. "Isso quando eu tava na Volvo. Eu queria fazer faculdade de Educação Física, sei lá... Isso era meu plano, porque lá o salário era alto, tipo dava para pagar uma faculdade, e ainda eu conseguiria pagar". A condição de aprendiz, que geralmente se dá em empresas de médio a grande porte, propicia ao jovem entrar em contato com um universo que dificilmente teria oportunidade de conhecer de outro modo.

O jovem se identifica com esses agentes; identifica-se com o papel de filho, de aprendiz (de um trabalho específico), de consumidor e de trabalhador de uma grande empresa. "Nossa! Shopping e cinema, eu nem agüentava mais entrar. Comprei CDs e roupas, e bastante porcaria também. Eu sei... eu... todo o meu salário caía no banco, daí eu tinha cartão. A gente não vê, eu não via o dinheiro entrando e não via o dinheiro saindo, era só pelo cartão, né?" O salário que recebe, por sua vez, propicia obter bens de consumo e freqüentar espaços que, devido a sua origem de classe e à idade, dificilmente conseguiria vivenciar

Ao mesmo tempo, conforma uma determinada forma de ser, de se ver e ver o mundo à sua volta, configurando-se em hábitos, comportamentos e atitudes dentro de um determinado papel. Conforme Ciampa (1998), as atividades dos indivíduos são normatizadas a partir da estrutura social, produzindo e conservando suas identidades que um dia foram pressupostas. Nesse sentido, seu projeto de vir a ser um trabalhador começa a ser tecido na rede social.

Sua identidade de trabalhador forja-se na aprendizagem de tarefas, na aquisição de saberes práticos e na vivência do papel de empregado. "Dependendo do tanto de serviço... era muito, muito serviço mesmo!, eu tinha que pegar no sábado. Digamos que eu tinha que ir, não precisa, né mas tinha que estar lá. Estar fazendo alguma coisa, que ele tem que fazer, tipo uma obrigação".

Uma vez posta, essa identidade tende a ser constantemente reposta e a permanecer, o que configura uma impossibilidade de ser para si. Com a reposição de outro papel social, o de desempregado, este é interiorizado pelo jovem como inferior, que o desqualifica perante a sociedade.

Jovens que pretendiam fazer uma carreira profissional, que construíram projetos de vida voltados para o futuro firmemente atrelados à busca de uma carreira com estabilidade, quando se vêem frente a uma súbita situação de desemprego suspendem seus projetos de vida. "Tentei o técnico, e os trinta melhores colocados na prova eram encaminhados para trabalhar na Bosch. Pra ficar na empresa e fazer, daí, um curso para crescer dentro da própria empresa".

$\mathrm{Na}$ busca de sua reinserção no mercado, almejam a reposição da identidade de trabalhador qualificado, enfrentando, então, a negação de um mercado de trabalho restrito inclusive para jovens qualificados. "Eu seria efetivado na empresa, mas eu acho que não fui, mais por causa disso, por causa da idade".

Constata-se, nesses jovens, uma crescente autoculpabilização, gerando um intenso sofrimento, expresso por sentimentos de vergonha e baixa autoestima, desânimo, distresse e desalento: “Tipo assim: o pessoal vai lá, faz o curso e quer trabalhar, não sei onde, tão tudo desempregado, tem curso mas não conseguem. Começou a bater aquele desânimo para mim, tipo eu não vou conseguir emprego. E não tenho condição de pagar um curso". 
Esses jovens desempregados temem o julgamento moral da sociedade. Não querem ser vistos como inúteis ou parasitas, pela família e comunidade de origem, querem conseguir emprego, querem manter a identidade que um dia foi posta. Observa-se uma tendência para o isolamento em suas casas, onde passam a maior parte do tempo, e ficam sem saber o que fazer para poder ser. Revelam-nos todo o sofrimento psicossocial da situação de excluídos do mercado de trabalho: "Agora eu sou um inútil... Ah, às vezes eu penso que... se eu fui azarado, digamos, de ser mandado embora. Hoje em dia eu não faço nada".

Esta culpabilização, gerada pela reiteração do sentimento de inadequação, reflete-se em limitadas possibilidades de ação deste jovem qualificado/desempregado; ele precisa de dinheiro para conseguir se qualificar cada vez mais e, sem trabalho, fica sem possibilidade de conseguir atender às exigências do mercado. $\mathrm{Na}$ menoridade, a culpabilização não possui impacto tão grande, pois ainda há o suporte da família e a distinção do papel social de ser menor, podendo permanecer, assim, identificando-se como esforçado estudante. “... porque quando eu era de menor, digamos, tinha o Senai. Quando você é de menor, você não paga. Só faz o teste, mas agora não; agora tem que pagar. Trabalhando eu tenho como ir atrás de curso, mas tenho que estar trabalhando, né?”

$\mathrm{Na}$ condição de desemprego, muitos dos jovens mudam seus projetos. Essas mudanças de trajetórias objetivas implicam que acorram a outras instituições, onde esperam encontrar mais segurança, submetendo-se a uma carreira militar ou a concursos públicos. "Eu tentei o exército, mas também não deu. Eu tinha um plano, se eu continuasse trabalhando lá...". Buscam cursos de informática, de idiomas e cursos técnicos que lhes tragam mais qualificação para o mercado. Outros permanecem desejando voltar aos postos anteriores de trabalho, dentro das suas qualificações e experiências adquiridas. "Eu tinha esperança de voltar lá... Eu queria fazer uma faculdade...". Contraditoriamente, apesar de saberem que a maioridade determina a rescisão do contrato de trabalho, nutrem grandes expectativas de permanecer na empresa, perspectivas de carreira e ascensão profissional. "Eu tinha esperança de ficar, tinha esperança de estabilidade, queria fazer uma carreira".

Tais expectativas são interiorizadas pela vivência na empresa, por meio das relações que estabeleceram com modelos de trabalhadores estáveis, que promovem a identificação do jovem com seu papel de trabalhador movido pela esperança de permanecerem empregados. "Se não hoje eu não sirvo para nada, fico só parado. Será que eu vou morar com o meu pai pro resto da vida? Se não me virar, vou ter que morar com ele pro resto da vida".

$\mathrm{Na}$ busca de entender como se dão as relações/contradições entre emoção, identidade, vivências e projetos vitais, compreendemos que existem de fato relações entre as trajetórias objetivas de inserção no mundo do trabalho, permeadas por emoções contraditórias de aceitação ou rebeldia inicial, que se convertem em conformismo e aceitação, legitimando a condição de excluídos. A identidade, neste processo, é ambígua: ora se iguala, ora se distingue da dos demais trabalhadores desempregados. "Eu vou procurando... eu não tenho uma área específica, assim, tenho um pouquinho de experiência na área gráfica e só. Eu não tenho experiência, né, não suficiente para o mercado de trabalho". Por terem alguma experiência profissional, sentem-se qualificados para o trabalho, desejam manter esta identificação com a posição de trabalhadores qualificados, que um dia foi posta.

Não obstante, a vivência de cada jovem, relacionada ao tempo de permanência na empresa e ao tempo de permanência na condição de excluídos, pode conformar mudanças em seu projeto de vida, repercutir na sua subjetividade. $\mathrm{O}$ trabalho qualificado passa a ter um sentido geral de direcionamento de seus projetos de futuro.

"Se você escolher um curso de Mecânica ou de Eletrônica, isso vai mudar a sua vida automaticamente. Você vai decidir o que vai ser quando crescer". Quando se identifica como trabalhador, recebendo as recompensas por seus esforços, o motivo de suas ações, além da própria sobrevivência e da possibilidade de consumo, é contribuir para o sustento familiar. Ao mesmo tempo, sente-se mais responsável por sua própria vida. O trabalho tem um sentido geral de promover a autonomia do jovem. "Eu acho que é mais por causa da idade... Tinha um monte de gente, tipo umas dez pessoas, todo mundo mais velho do que eu, e com família, tipo com casa e com filho. Daí eu tinha dezenove anos, eu ia fazer dezenove, daí contou mais a idade, o peso... tipo eles preferem quem tem uma família para carregar. Mas será que algum dia eu vou poder ter uma família?” 


\section{Considerações finais}

Constata-se que o desemprego juvenil é produto de uma sociedade fundada num mercado capitalista, que transformou em mercadoria a força de trabalho. A vivência do desemprego, que determina um destino de classe, exige reflexão sobre suas causas, isso porque oportunidades objetivas diferentes correspondem a sistemas de comportamentos, sentimentos e atitudes diferentes relativos a si mesmo e à sociedade.

Diante da fragmentação social em que vivemos, deparamo-nos com um conjunto de desigualdades de oportunidades, que fomentam distinções classificadoras entre os jovens e modificam sua experiência juvenil conforme sua posição social. Aí se alternam menores x maiores, trabalho intelectual $\mathrm{x}$ trabalho manual, qualificados $\mathrm{x}$ desqualificados, empregados $\mathrm{x}$ desempregados.

Ironicamente, enquanto se submete a essas condições em busca de inclusão, o contrato de trabalho também determina sua exclusão com a maioridade legal (aos 18 anos, o vínculo com a empresa é cortado automaticamente), na medida em que não prevê incentivos para a empresa efetivar pós-contrato de aprendizagem; a vivência do desemprego juvenil qualificado é determinada não só pela maioridade, mas também por fatores como crise econômica e "novo paradigma de produção", assentado na "especialização flexível", gerando, além do desemprego estrutural, novas demandas de adaptação ao competitivo mercado de trabalho. Coloca-se em xeque o trabalhador especializado, exige-se um trabalhador cada vez mais polivalente, com amplas habilidades cognitivas e comportamentais, criatividade, cooperação, liderança para vencer as novas demandas da produção, além de conhecimentos de informática e línguas estrangeiras, não acessíveis às camadas mais desfavorecidas. Surge um novo paradoxo: o jovem trabalhador qualificado, porém já desempregado.

Gostaríamos de pontuar que, embora não fosse nosso objetivo específico abordar mais profundamente a categoria consciência, verificamos, resgatando a narrativa dos jovens, que estes são capazes de articular movimentos de compreensão de si e da realidade social em maior ou menor grau de entendimento da realidade que os cerca, tal como expresso nesta fala: "O desemprego está brabo", ou ainda: "Acho que não tem vaga para todo mundo".

Mesmo reconhecendo várias limitações na construção da visão da vivência do desemprego em jovens aprendizes, e certas de que estamos longe de esgotar o tema, acreditamos que conseguimos dar maior visibilidade a como se processam as políticas públicas de inserção profissional. Devemos refletir mais profundamente sobre as mobilizações de preparo para o futuro do jovem, em confronto com a formação profissional como um processo constitutivo de determinadas identidades profissionais.

Em suma, concluímos que o mercado capitalista dita as regras de conduta e comportamentos, promovendo uma identidade valorizada de trabalhador. O trabalho é sentido como dever, obrigação social; é não ter tempo, é ser responsável, é ser digno. Por outro lado, a vivência do desemprego, a exclusão do mercado promovem a interiorização de uma imagem negativa, desmoralizante, carregada de sentimentos de inferioridade e inadequação. Estar desempregado é não ter utilidade, não ter lugar para ser, é ser um peso para a família, um parasita, um não-ser.

O curso de aprendizagem é não apenas um meio de inclusão no mundo do trabalho, mas também um meio para a expressão e transformação da identidade dos jovens em múltiplos aspectos. Os jovens aprendizes estabeleceram os sinais de distinção profissional em torno de dois eixos: qualificação (tipo de especialidade adquirida) e experiência (vivência em um emprego). Em conseqüência, considera-se que o jovem aprendiz desempregado busca uma carreira profissional de acordo com a reposição da identidade um dia posta. Além do sofrimento psicológico, o desemprego gera mudanças significativas de trajetórias.

Entre os que podem custear suas novas qualificações, alguns jovens já desistiram de seus projetos de vida mais ambiciosos. Para estes jovens aprendizes desempregados, o trabalho se situa no projeto de vida, como uma estratégia para tornarse sustentável financeiramente. A esses aprendizes resta apenas a expectativa de conseguir um emprego. Aos excluídos do mercado de trabalho "qualquer coisa serve" para poder conseguir lutar, "para poder criar a minha vida", para resgatar a dignidade e a razão de viver. 


\section{Referências}

Abib, L. A. D. (2001). Apresentação. In: M. C. S., Pereira. (Org.). Cidadania, educação e subjetividade. (pp. 8). Londrina: UEL.

Bauer \& G. Gaskell (Org.). (2002). Pesquisa qualitativa com texto, imagem e som: um manual prático. Petrópolis, Rio de Janeiro: Vozes.

Carreteiro, T. C. (2002). A doença como projeto. In B. Sawaia (Org.). As artimanhas da exclusão: Análise psicossocial e ética da desigualdade social (pp.87-95). Rio de Janeiro: Vozes.

Ciampa, A. C. (1987). Identidade. In W. Codo \& S. T. M. Lane (Orgs.). Psicologia social: O homem em movimento (pp.58-75). São Paulo: Brasiliense.

Ciampa, A. C. (1998). Identidade humana como metamorfose: a questão da família e do trabalho e a crise de sentido no mundo moderno. Texto de comunicação oral apresentado em 23 de agosto, na mesa-redonda "Família, Cultura e Sociedade", promovida pela Universidade de São Marcos. Revista Interações, 3(6).

D’Ângelo, D. O. S. H. (2000). Proyeto de vida como categoria básica de interpretacion de la identidad individual e social. Universidad de La Havana. Revista Cubana de Psicologia, 17(3):270-275.

Heller, A. (1993). Teoria de los sentimientos. Barcelona: Fontamara.

IPEA - Instituto de Pesquisa Econômica Aplicada. (2003). Mercado de trabalho: conjuntura e análise. (pp. 54-66). Rio de Janeiro: IPEA.

Brasil. Presidência da República. (2000). Lei sobre menores aprendizes n. ${ }^{\circ}$ 10.097/2000. Brasília: Casa Civil, Recuperado em 15 jun. 2006: http:/ /www. Planalto. Gov. Br/ccivil_03/Leis/ L10097.htm

Maturana, H. (1999). Emoções e linguagem na educação e na política. Belo Horizonte: UFMG.

Minayo, M. C. S. (Org.). (2002). Pesquisa social: Teoria, método e criatividade. Petrópolis: Vozes.

Organização Internacional do trabalho (2001). Desemprego Juvenil no Brasil: Em busca de opções à luz de algumas experiências internacionais. Brasília: OIT.
Pochman, M. (2000). O trabalho sob fogo cruzado: Exclusão, desemprego e precarização no final do século. São Paulo: Contexto.

Rimé, B. (1993). Le partage social dês emotions: Neuchâtel. Paris: Delachaux \& Niestlé.

Sawaia, B. (1995). Dimensão ético-afetiva do adoecer da classe trabalhadora. In S. M. Lane \& B. B. Sawaia (Org.). Novas veredas da psicologia social. São Paulo: Brasiliense.

Secretaria de Estado do Trabalho, Emprego e Promoção Social. (2003). Coordenação Estadual do SINE - CESINE-PR. Caderno Estatístico sobre o Mercado de Trabalho de Curitiba, 1(2):75.

Velho, G. (1999). Projeto e metamorfose, antropologia das sociedades complexas. Rio de Janeiro: Jorge Zahar.

Vigotsky, L. S. (1998). Pensamento e linguagem. São Paulo: Martins Fontes.

Recebido em: 28/06/2006
Received in: 06/28/2006
Aprovado em: 02/10/2006
Approved in: 10/02/2006 